\title{
Congenital Frontal-Vault Depression in a Neonate
}

Takagi $\mathbf{S}^{1 *}$, Inoue $\mathbf{H}^{2}$, Suzuki $\mathbf{S}^{1}$, Morita $\mathbf{A}^{1}$, Kawakami $\mathbf{Y}^{\mathbf{1}}$, Akita $\mathbf{S}^{\mathbf{1}}$ and Ohjimi $\mathbf{H}^{\mathbf{1}}$

${ }^{1}$ Department of Plastic and Reconstructive Surgery, Fukuoka University, J apan

${ }^{2}$ Department of Pediatrics, Kyushu University, J apan

*Corresponding author: Satoshi Takagi, Department of Plastic and Reconstructive Surgery, Fukuoka

University, J apan

Received: December 28, 2018; Accepted: February 08, 2019; Published: February 15, 2019

\section{Abstract}

Congenital depression of the fetal skull unassociated with any acute trauma, typically involving the temporal or parietal areas, is rare. The need for surgical intervention for the deformity remains controversial, particularly with respect to an indentation located in the forehead area. Herein, we report a case of a congenital frontal-vault depression in a neonate that was managed conservatively for nearly 18 months. The shape of the infant's skull resolved spontaneously with no active intervention. When congenital vault depression is diagnosed, watchful waiting for a year or more may be advisable because spontaneous resolution can be expected.

Keywords: Frontal-vault depression; Neonate; Congenital; Atraumatic

\section{Case Presentation}

A female infant was delivered by spontaneous cephalic delivery at 40 weeks of gestation in another hospital. Her birth weight was $3584 \mathrm{~g}$ and her Apgar scores were 9 and 10 at 1 and $5 \mathrm{~min}$, respectively. At birth, she was clinically noted to have an indentation in the right frontal region. Otherwise, her skull had a typical shape.

The infant was at first assumed to have a ping-pong fracture, but no obstetric extraction instruments had been used during the delivery. There was no history of trauma to the mother's abdomen during pregnancy and no myoma or tumor was present in her uterus. Computed Tomography (CT) of the infant's skull 3 days after her birth revealed a bony depression of the right frontal bone (Figure 1). The indentation was $40 \mathrm{~mm}$ in diameter and $5 \mathrm{~mm}$ in depth at its center. There was no cerebral edema or intracranial hemorrhage beneath the depression. A bony fracture line was not apparent in the depressed area.

She was brought to our outpatient clinic for the first time at 33 days of age for a second opinion (Figure 2). On physical examination, her right forehead was deeply indented. The base of the dent felt like solid bone and was non-mobile. Though her developmental milestones and neurological examination were normal, the deformity disfigured her facial appearance and medical intervention was strongly desired to improve her appearance.

We considered the use of cranial molding therapy with an orthotic helmet as a good non-surgical approach. Before starting helmet therapy, we needed to wait for a several months until she was able to
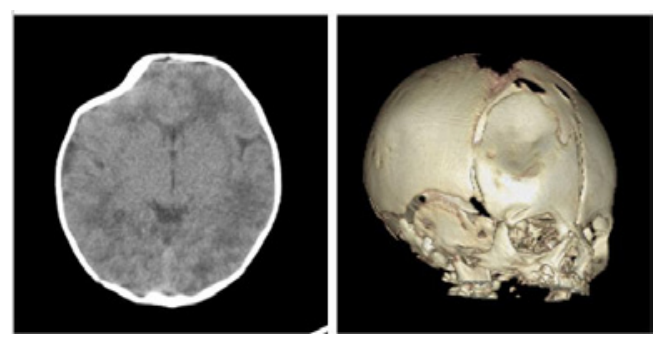

Figure 1: Computed tomography showing indentation of the right frontal bone. (a)
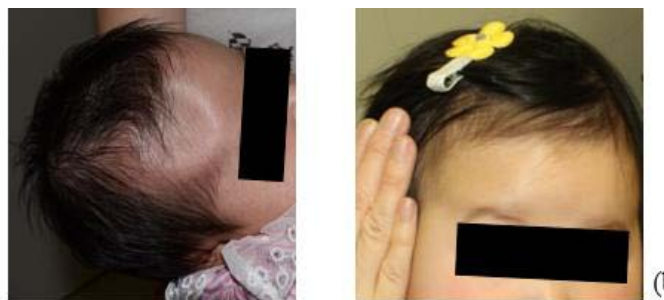

(b)

(c)
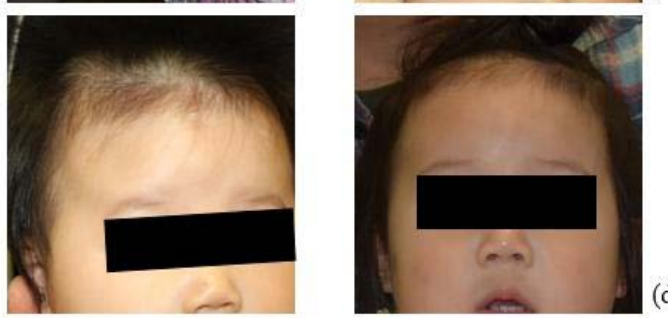

(d)

Figure 2: Spontaneous resolution ocuured by the age of 12 months. (a) 1 month after birth, (b) 4 months, (c) 8 months, (d) 18 months.

hold up her head steadily. Over the course of monthly follow-ups, we observed that the depression became shallow and mild. We therefore decided to continue watchful observation over implementation of helmet therapy.

Finally, by 18 months of age, the depression had completely resolved, with the child meeting all developmental milestones (Figure 2). Because of ethical reasons and unwillingness of the parents, repeat imaging of the skull was not performed.

\section{Discussion}

Congenital vault depression is a rare occurrence with an incidence of almost 1 in 10,000 live births. As the fetal bones are easily deformable, prolonged external pressure on the fetal skull in the uterus can result in an osseous indentation. Possible causes include a bony prominence of the pelvis, a uterine myoma, the fetus' own hand, or the body part of a twin. A depression linked to obstetric trauma is referred to ping-pong fracture of the skull, which presents in a similar manner. As our case was delivered uneventfully with no obstetric instrument usage and no crack or break line was not detected in the osseous indentation on CT, we diagnosed the patient as having a

Austin J Surg - Volume 6 Issue 4 - 2019

ISSN : 2381-9030 | www.austinpublishing group.com

Takagi et al. @ All rights are reserved
Citation: Takagi S, Inoue H, Suzuki S, Morita A, Kawakami Y, Akita S, et al. Congenital Frontal-Vault Depression in a Neonate. Austin J Surg. 2019; 6(4): 1166. 
congenital skull depression, otherwise known as faulty fetal packing.

On a review of the available literature, congenital skull depression mostly occurred in the parietal bones and much less in the frontal bones; however, the mechanism is still unclear [1-4]. When compared to a depression in the hairy temporal area, a deformity in the bald frontal area disfigures the neonate's facial appearance and is conspicuous to people around. It is understandable that parents hold high expectations for subsequent treatment.

A number of published cases have demonstrated spontaneous resolution of the depression within 4 months without any cosmetic or neurodevelopmental sequelae [1-4]. However, all of these reports are for congenital skull depression on the parietal or temporal area and it is unclear whether the finding hold true for congenital frontal-vault depression. Cizmeci surgically treated a case with forehead deformation, extremely similar to present case, and gained an excellent result with a single intervention [5]. After considerable discussion with multidisciplinary medical professionals and the patient's family, watchful observation was employed in our case. We were always ready to utilize surgical interventions or provide a trial usage of cranial molding helmet, only if the depression showed no spontaneous resolution or stopped improving.

At 4 months of age, the deformity became mild but was still apparent. Eventually, nearly 18 months were needed until an esthetically acceptable shape was obtained and no trace of the previous deformity was observable. Generally, a neonate sleeps on its back for most of the day, during which time the cerebral parenchyma would be positioned at the back of the skull. The brain can easily come in contact with or slightly push the inner table of the depressed skull area at the parietal region, but not at the frontal region. This might provide an explanation for the difference in the period required for the spontaneous resolution of congenital skull depression.

In conclusion, when a congenital vault depression is diagnosed, watchful waiting for over 1 year is recommended - because spontaneous resolution may be expected.

\section{Acknowledgement}

We would like to thank Editage (www.editage.jp) for English language editing.

\section{References}

1. Agrawal SK, Kumar P, Sundaram V. Congenital depression of the skull in neonate: a case of successful conservative management. Journal of child neurology. 2010; 25: 387-389.

2. Flannigan C, O'Neill C. Faulty fetal packing. BMJ case reports. 2011.

3. Shamsian N, Robertson AT, Anslow P. Congenital skull indentation: a case report and review of the literature. BMJ case reports. 2012.

4. Tayeh C, Bali B, Milad N, Najjar M. Congenital depression of the skull in a neonate. BMJ case reports. 2016.

5. Cizmeci MN, Kanburoglu MK, Cemil B, Gokce EC, Tatli MM. Ping pong fracture in the newborn: illustration of a case. Acta neurologica Belgica. 2014; 114: 69-70.
Austin J Surg - Volume 6 Issue 4 - 2019

ISSN : 2381-9030 | www.austinpublishing group.com

Takagi et al. (C) All rights are reserved
Citation: Takagi S, Inoue H, Suzuki S, Morita A, Kawakami Y, Akita S, et al. Congenital Frontal-Vault Depression in a Neonate. Austin J Surg. 2019; 6(4): 1166 